\title{
Development of UHPLC/Q-TOF Analysis Method to Screen Glycerin for Direct Detection of Process Contaminants 3-Monochloropropane-1,2-diol Esters (3-MCPDEs) and Glycidyl Esters (GEs)
}

\author{
Lauren Girard ${ }^{1}$, Kithsiri Herath ${ }^{1}$, Hernando Escobar ${ }^{1}$, Renate Reimschuessel ${ }^{2}$, Olgica Ceric ${ }^{2}$ and \\ Hiranthi Jayasuriya ${ }^{1, *}$
}

1 Center for Veterinary Medicine, Office of Research, Division of Residue Chemistry, Food and Drug Administration, 8401 Muirkirk Road, Laurel, MD 20708, USA; Lauren.Girard@fda.hhs.gov (L.G.); Kithsiri.Herath@fda.hhs.gov (K.H.); Hernando.EscobarLoaiza@fda.hhs.gov (H.E.)

2 Center for Veterinary Medicine, Office of Research, Veterinary Laboratory Investigation \& Response Network, Food and Drug Administration, 8401 Muirkirk Road, Laurel, MD 20708, USA;

Renate.Reimschuessel@fda.hhs.gov (R.R.); Olgica.Ceric@fda.hhs.gov (O.C.)

* Correspondence: Hiranthi.Jayasuriya@fda.hhs.gov; Tel.: +1-240-402-6688

check for updates

Citation: Girard, L.; Herath, K.; Escobar, H.; Reimschuessel, R.; Ceric, O.; Jayasuriya, H. Development of UHPLC/Q-TOF Analysis Method to Screen Glycerin for Direct Detection of Process Contaminants

3-Monochloropropane-1,2-diol Esters (3-MCPDEs) and Glycidyl Esters (GEs). Molecules 2021, 26, 2449. https://doi.org/10.3390/molecules 26092449

Academic Editors: Muhammad Ilias and Dhammika Nanayakkara

Received: 22 February 2021

Accepted: 9 April 2021

Published: 22 April 2021

Publisher's Note: MDPI stays neutral with regard to jurisdictional claims in published maps and institutional affiliations.

Copyright: (c) 2021 by the authors. Licensee MDPI, Basel, Switzerland. This article is an open access article distributed under the terms and conditions of the Creative Commons Attribution (CC BY) license (https:// creativecommons.org/licenses/by/ $4.0 /)$.

\begin{abstract}
The U.S. Food and Drug Administration's (FDA's) Center for Veterinary Medicine (CVM) has been investigating reports of pets becoming ill after consuming jerky pet treats since 2007 . Renal failure accounted for $30 \%$ of reported cases. Jerky pet treats contain glycerin, which can be made from vegetable oil or as a byproduct of biodiesel production. Glycidyl esters (GEs) and 3-monochloropropanediol esters (3-MCPDEs) are food contaminants that can form in glycerin during the refining process. 3-MCPDEs and GEs pose food safety concerns, as they can release free 3-MCPD and glycidol in vivo. Evidence from studies in animals shows that 3-MCPDEs are potential toxins with kidneys as their main target. As renal failure accounted for 30\% of reported pet illnesses after the consumption of jerky pet treats containing glycerin, there is a need to develop a screening method to detect 3-MCPDEs and GEs in glycerin. We describe the development of an ultra-high-pressure liquid chromatography/quadrupole time-of-flight (UHPLC/Q-TOF) method for screening glycerin for MCPDEs and GEs. Glycerin was extracted and directly analyzed without a solid-phase extraction procedure. An exact mass database, developed in-house, of MCPDEs and GEs formed with common fatty acids was used in the screening.
\end{abstract}

Keywords: UHPLC/Q-TOF-MS analysis; glycerin; process contaminants; 3-monochloropropane-1,2diol esters; glycidyl esters

\section{Introduction}

In the late summer of 2007, the FDA became aware of reports of illness in dogs after consuming jerky pet treats (JPTs) [1,2]. For more than 10 years, the FDA dedicated extensive resources to the JPT investigation, including reviewing and investigating consumer complaint cases and collecting and testing JPT products (including products consumed by affected dogs) and animal diagnostic samples. Most of the cases (approximately 60\%) involved gastrointestinal symptoms. Renal dysfunction or failure accounted for $30 \%$ of the reported cases, with a smaller subset reporting Fanconi syndrome, a dysfunction of the proximal renal tubules of the kidney in which glucose, amino acids, uric acid, phosphate, and bicarbonate are passed into the urine instead of being reabsorbed [3]. Fanconi syndrome is linked to exposure to certain toxins, medications, and infections in dogs as well as in people [4]. Exposure to toxins and drugs, including ethylene glycol (antifreeze), metals, chemotherapeutics, and expired tetracyclines and other antibiotics can damage the proximal renal tubule of the kidney $[3,5]$. Hooper commented that proximal renal tubular 
cells are exposed to the highest concentrations of renal-damaging substances, more so than distal tubular cells [6]. Damaged or dysfunctional proximal tubule cells can become "leaky", allowing glucose, bicarbonate, amino acids, and other substances to cross into the urine by hindering normal resorptive functions.

JPTs are often made from dried chicken (or duck) meat or sweet potatoes. As of 1 September 2018, FDA's Veterinary Laboratory Investigation and Response Network (Vet-LIRN) had collected and performed testing on more than $650 \mathrm{JPT}$ samples related to more than 550 consumer complaints, as well as more than 400 retail samples of unopened product bags obtained from a store or shipment. Vet-LIRN did not subject every sample to the entire battery of testing due to limited resources and product availability. Sample testing was targeted based on the concerns with a particular product or brand and the symptoms displayed by the pet that consumed the product. The product-based testing plans targeted the main ingredients (chicken, duck, or sweet potatoes) and considered other information on the product labels, such as additional ingredients and/or their contaminants. For example, Vet-LIRN investigation revealed that some products contained glycerin (as high as $20 \%$ ), although it was not listed on the label, and conducted additional testing for glycerin to follow up on this finding [2]. Glycerin is often added to JPTs to prevent excessive drying and improve the product's texture.

Glycerin is also used to produce many other products including drugs, cosmetics, foods, tobacco products, sweeteners, and toiletries. As glycerin may be produced during biodiesel production and is subjected to a refining process, it is important to ensure that there are methods to detect potential toxic contaminants that could arise during manufacture.

Recently we published a UHPLC/Q-TOF method to screen crude glycerin for toxic phorbol ester contaminants [7]. Another group of compounds that could be contaminants in glycerin comprises 3-monochloropropane-1,2-diol (MCPD), its esters (MCPDEs), and glycidyl esters (GEs), which carry a reactive epoxide moiety. These compounds are formed during the industrial processing of oils in the presence of chloride ions, glycerin, and high temperatures [8]. In 2015, Vet-LIRN tested 74 JPT samples for MCPD and found that 31 samples tested positive at concentrations ranging from 0.027 to $0.352 \mathrm{ppm}$. The significance of this finding was not clear, although the review of the available scientific literature did not suggest that these MCPD levels in JPTs would cause illness in pets.

Free MCPDs are present in the low $\mathrm{mg} / \mathrm{kg}$ range in many foodstuffs such as acidhydrolyzed vegetable protein, soy sauces, crackers, bread, toast and other bakery products, malt, meat products, and soups [9-13]. In most foodstuffs, only a small percentage of 3-MCPD is present as free 3-MCPD, while the majority is present as MCPDEs. Based on positive findings of MCPD in JPTs, Vet-LIRN investigation showed the need to evaluate JPTs and glycerin for their presence of MCPDEs; however, this type of testing is not available domestically.

An extensive review about 3-MCPDE toxicity was published by the Joint FAO/WHO Expert Committee on Food Additives (JEFCA) in 2016 [14]. In 2018, the same regulatory body established a group total daily intake (TDI) of $2 \mu \mathrm{g} / \mathrm{kg}$ bw / day for 3-MCPD and its esters [15]. 3-MCPDEs are potentially toxic compounds with kidneys as their main target, according to reports from studies in animals. In Wistar rats or Swiss mice dosed with different MCPDEs, nephrotoxic degenerative and inflammatory changes in kidneys were evidenced by organ weight increase, glomerular lesions, tubulotoxicity (necrosis, tubular epithelial hyperplasia, and multifocal hypertrophy), cellular infiltration in interstitial spaces, and fibrosis [16,17]. Rat bioavailability studies show that 3-MCPDEs are completely hydrolyzed by enzymatic reactions in the gastrointestinal tract with release of 3-MCPD to be distributed to blood, organs, and tissues [18,19]. From short-term studies in rats and mice, the most affected organ after 3-MCPD induced toxicity was the kidney, with similar organ degenerative changes found for parent 3-MCPD esters [20]. A more recent report describes induced acute renal failure with nephrotoxic structural changes after oral administration of 3-MCPD in male albino rats in a period as short as 7 days [21]. 
Potential severe toxicological effects induced in animals with the presence of 3MCPDEs have raised concerns about the level of exposure to these food contaminants. Strong evidence shows that glycidol and GEs are potential genotoxic carcinogen agents and probably carcinogenic to humans [22]. Studies on bioavailability have shown that GEs are hydrolyzed (de-esterified) during digestion, and the free glycidol is almost completely released [14]. The GEs are therefore treated like glycidol from a toxicological point of view. Due to the genotoxic potential of glycidol, it is not possible to derive any safe intake quantities for GEs.

Due to the potential renal toxicity of MCPDEs, which are derived from MCPD, and the carcinogenicity of glycidol derived from GEs, we focused our method development efforts to screen glycerin for MCPDEs and GEs.

\section{Results and Discussion}

Glycerin is the major byproduct of biodiesel production. Centrifugation or gravitational settling is used to separate biodiesel from glycerin after transesterification [23,24]. The lower glycerin phase consists of glycerol and other impurities such as methyl esters; water; alcohol; salts; and unreacted mono-, di-, and triglycerides. The crude glycerin is subjected to an expensive refining process that includes treatments such as bleaching, deodorizing, and ion exchange. Contaminants such as free fatty acids and their salts are removed to meet the USP standards to be used in food production. Some steps such as the deodorization step are carried out at elevated temperatures of more than $200{ }^{\circ} \mathrm{C}$.

The main factors for the formation of MCPDEs and GEs are the presence of chloride ions; glycerin; and tri-, di-, or monoacylglycerides and high temperatures. As glycerin is subjected to these conditions during production and refining, it is possible that it is tainted with such process contaminants.

Many edible oils also undergo a similar refining process to improve their quality. Evidence exists in the scientific literature to show the formation of MCPDEs and GEs during the industrial processing of oils [8,25-27]. These contaminants may be harmful to health and, therefore, undesirable in foods. There are many published studies to screen for these ester contaminants in edible oils [28-30], but to our knowledge, there are no methods published yet for glycerin.

The determination of MCPDEs is complicated due to structural diversity. Considering the possible positional isomers of $\mathrm{MCPD}$, the formation of about 100 different ester compounds is possible. However, because of the relative abundance of the fatty acids, only seven esters (lauric, myristic, palmitic, stearic, oleic, linoleic, and linolenic acids) are considered in food analysis [13]. For GEs, the number of ester structures is smaller, caused by its single hydroxyl group and lack of positional isomers.

LC method development was challenging due to the polarity range of the compounds. We tried to use ACN/water gradients spanning $5-100 \%$ ACN in 15 min with formic acid in both solvents. The GEs and the mono-MCPDEs, which are polar, eluted from the column, but the nonpolar di-MCPDEs did not elute from the column with this solvent gradient. We also tried other solvent gradients reported in the literature such as $\mathrm{ACN} / \mathrm{MeOH} /$ water as solvent $\mathrm{A}$ and acetone as solvent $\mathrm{B}$ ramping up to $60 \%$ acetone [31]. Even though the nonpolar di-MCPDEs eluted from the column with this solvent gradient, the peak shapes were broad. The IPA / $8 \%$ aqueous methanol with formic acid step gradient used in the LC is a modification of a method reported in the literature for the analysis of GEs and mono- and di-MCPDEs as contaminants in edible oils [28]. LC parameters including mobile phase, column type, column temperature, flow rate, and gradient conditions were varied to establish the optimal liquid chromatography. The optimized step gradient allowed us to retain all three classes of compounds of differing polarities on the column as well as elute the most nonpolar di-MCPDEs within the gradient.

Even though we used six representative compounds of GEs and MCPDEs in our mixed standard, we analyzed many others in our study. The most polar 1-lauroyl-3chloropropanediol and the most nonpolar 1,2-distearoyl-3-chloropropanediol eluted within 
our gradient. The LC retention times ranged from 2.3 to $10.3 \mathrm{~min}$ for the six compounds in our mixed standard using this gradient (Figure 1). Average responses in Table 1 indicated that the sodium adducts were much more dominant than the protonated adducts for all six compounds. This is true and consistent for all GEs and MCPDEs we analyzed during this study. This was an important observation that allowed us to screen for lower levels of MCPDEs by detecting unique ion clusters containing chlorine with sodium adducts.

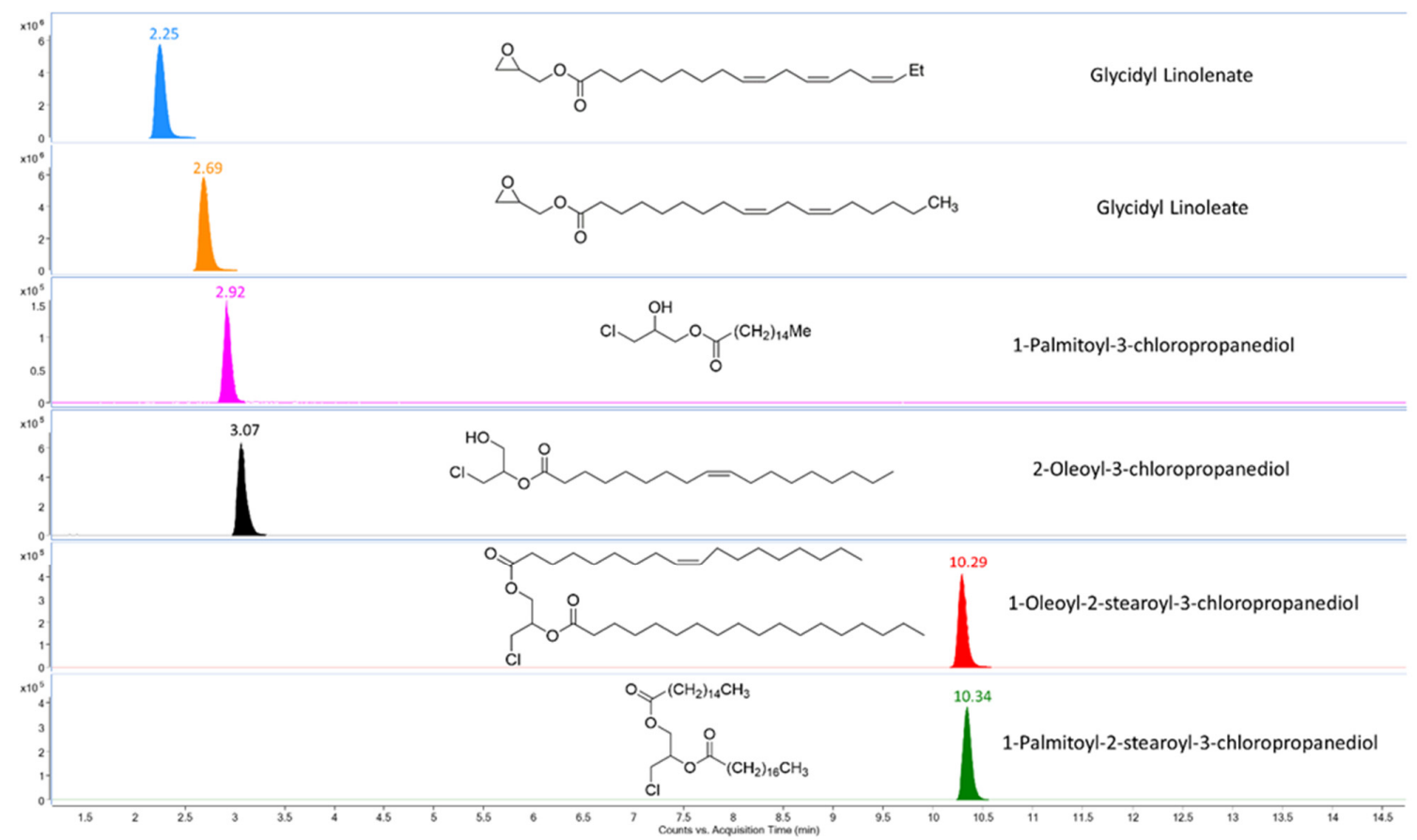

Figure 1. Extracted ion chromatograms for the mixed standard of glycidyl esters (GEs) and 3-monochloropropanediol esters (MCPDEs) in the glycerin matrix.

Table 1. Average response for protonated and sodium adducts of GEs and MCPDEs in the mixed standard.

\begin{tabular}{cccc}
\hline Compound & Exact Mass & $\mathbf{( M + H )}$ & $\mathbf{( M + N a )}$ \\
\hline Glycidyl linolenate & 334.2508 & $2,209,671$ & $34,331,876$ \\
\hline Glycidyl linoleate & 336.2664 & $3,308,840$ & $45,741,444$ \\
\hline 1-Palmitoyl-3-chloropropanediol & 348.2431 & 0 & $1,517,938$ \\
\hline 2-Oleoyl-3-chloropropanediol & 374.2588 & 116,159 & $6,265,336$ \\
\hline 1-Oleoyl-2-stearoyl-3-chloropropanediol & 640.5197 & 0 & $7,484,321$ \\
\hline 1-Palmitoyl-2-stearoyl-3-chloropropanediol & 614.5041 & 0 & $8,217,162$ \\
\hline
\end{tabular}

\subsection{Calibration Curves}

Calibration curves were generated for selected GEs and mono- and di-MCPDEs in both solvents, methanol and glycerin-matrix (Figure 2). All calibration standards were analyzed in triplicate over the concentration range of 10 to $400 \mathrm{ppb}$ for MCPDEs and 2 to $100 \mathrm{ppb}$ for GEs. A quadratic regression algorithm with no weighting was used to compare the standard curves in solvent versus matrix. The average correlation coefficients for all calibration curves were $>0.997$. We observed matrix enhancement for di- and mono-MCPD esters; however, glycidyl esters showed a matrix suppression effect.

The calibration curves constructed for the mixed standard were used to determine the matrix effect. The calibration standards were used to validate the data analysis process. 


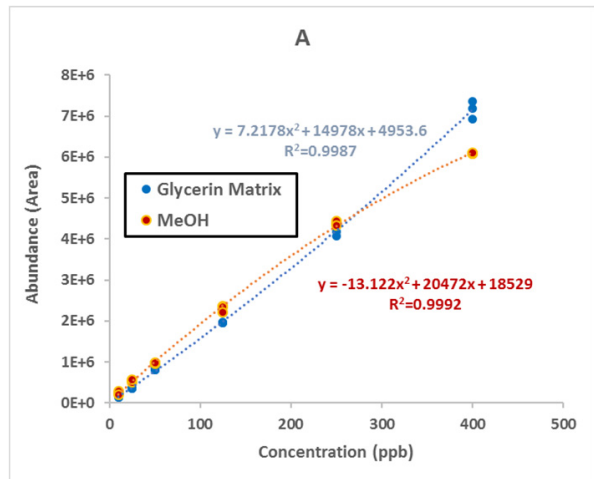

(a)

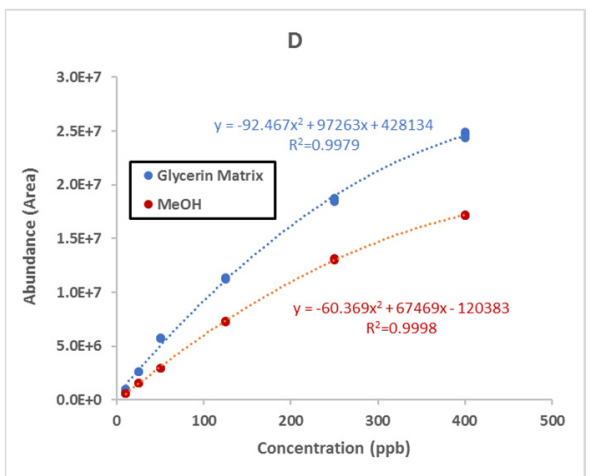

(d)

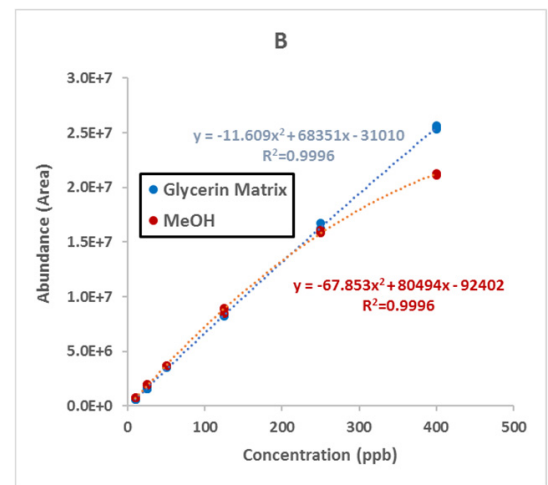

(b)

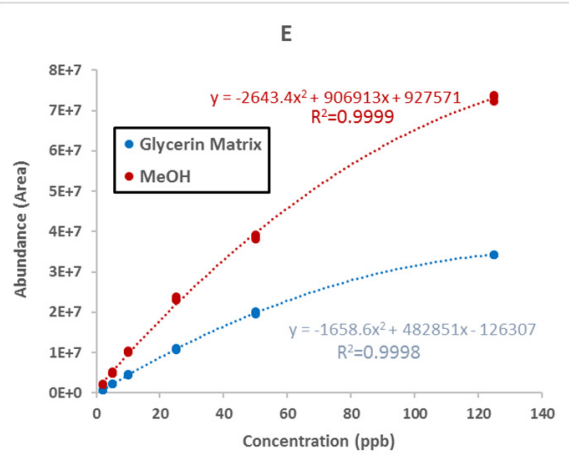

(e)

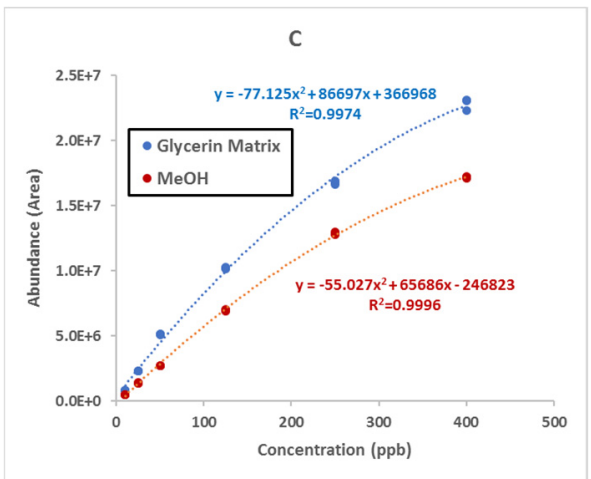

(c)

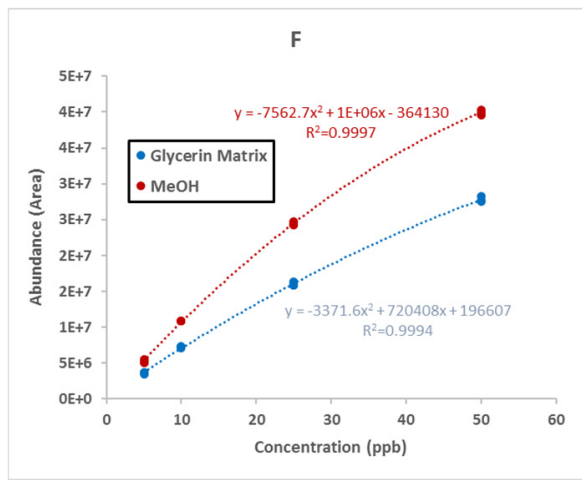

(f)

Figure 2. Calibration curves prepared in glycerin matrix and methanol for (a) palmitoyl-chloropropanediol, (b) oleylchloropropanediol, (c) 1-oleoyl-2-stearoyl-2-chloropropanediol, (d) 1-palmitoyl-2-stearoyl-3-chloropropanediol, (e) glycidyl linoleate, and (f) glycidyl linolenate.

Data analysis was performed with the Mass Hunter Qualitative Analysis software (B.06.00) using FbF (find by formula) algorithm to screen for compounds in the glycerin extracts using an in-house MCPDE and GE exact mass database as the formula source (Table 2). The in-house database was constructed by adding the exact masses of all possible esters of GEs and mono- and di-MCPDEs of lauric, myristic, palmitic, linolenic, linoleic, oleic, and stearic acids. The algorithm $\mathrm{FbF}$ was restricted to the $m / z$ range of $50-1000 \mathrm{Da}$ and completed within the timespan of the LC gradient. Singly charged ions and a minimum peak height of 10,000 ion counts were selected for FbF. The allowed adduct ions included $\mathrm{H}^{+}$and $\mathrm{Na}^{+}$. FbF algorithm scores the database matches based on the similarity of each of the isotopic masses (Mass Match), isotope ratios (Abundance Match), isotope spacing (Spacing Match), and optionally, the retention time (RT Match).

Table 2. Database of MCPDEs and GEs.

\begin{tabular}{|c|c|c|}
\hline Formula & Exact Mass & Compound Name \\
\hline \multicolumn{2}{|c|}{ MCPD monoesters } & \\
\hline $\mathrm{C} 17 \mathrm{H} 33 \mathrm{ClO} 3$ & 320.2118 & Myristoyl-chloropropanediol \\
\hline $\mathrm{C} 15 \mathrm{H} 29 \mathrm{ClO} 3$ & 292.1805 & Lauroyl-chloropropanediol \\
\hline $\mathrm{C} 19 \mathrm{H} 37 \mathrm{ClO} 3$ & 348.2431 & Palmitoyl-chloropropanediol \\
\hline $\mathrm{C} 21 \mathrm{H} 41 \mathrm{ClO} 3$ & 376.2744 & Stearoyl-chloropropanediol \\
\hline $\mathrm{C} 21 \mathrm{H} 39 \mathrm{ClO} 3$ & 374.2588 & Oleyl-chloropropanediol \\
\hline $\mathrm{C} 21 \mathrm{H} 37 \mathrm{ClO} 3$ & 372.2431 & Linoleoyl-chloropropanediol \\
\hline $\mathrm{C} 21 \mathrm{H} 35 \mathrm{ClO} 3$ & 370.2275 & Linolenoyl-chloropropanediol \\
\hline
\end{tabular}


Table 2. Cont.

\begin{tabular}{|c|c|c|}
\hline Formula & Exact Mass & Compound Name \\
\hline \multicolumn{2}{|c|}{ MCPD diesters } & \\
\hline $\mathrm{C} 35 \mathrm{H} 67 \mathrm{ClO} 4$ & 586.4728 & Di-palmitoyl-chloropropanediol \\
\hline $\mathrm{C} 27 \mathrm{H} 51 \mathrm{ClO} 4$ & 474.3476 & Di-lauroyl-chloropropanediol \\
\hline $\mathrm{C} 29 \mathrm{H} 55 \mathrm{ClO} 4$ & 502.3789 & Lauroyl-myristoyl-chloropropanediol \\
\hline $\mathrm{C} 33 \mathrm{H} 57 \mathrm{ClO} 4$ & 552.3945 & Lauroyl-linolenoyl-chloropropanediol \\
\hline $\mathrm{C} 33 \mathrm{H} 59 \mathrm{ClO} 4$ & 554.4102 & Lauroyl-linoleoyl-chloropropanediol \\
\hline $\mathrm{C} 39 \mathrm{H} 67 \mathrm{ClO} 4$ & 634.4728 & Di-linoleoyl-chloropropanediol \\
\hline $\mathrm{C} 39 \mathrm{H} 63 \mathrm{ClO} 4$ & 630.4415 & Di-linolenoyl-chloropropanediol \\
\hline $\mathrm{C} 35 \mathrm{H} 61 \mathrm{ClO} 4$ & 580.4285 & Linolenoyl-myristoyl-chloropropanediol \\
\hline $\mathrm{C} 31 \mathrm{H} 59 \mathrm{ClO} 4$ & 530.4102 & Di-myristoyl-chloropropanediol \\
\hline $\mathrm{C} 31 \mathrm{H} 59 \mathrm{ClO} 4$ & 530.4102 & Lauroyl-Palmitoyl-chloropropanediol \\
\hline $\mathrm{C} 33 \mathrm{H} 61 \mathrm{ClO} 4$ & 556.4258 & Lauroyl-Oleoyl-chloropropanediol \\
\hline $\mathrm{C} 39 \mathrm{H} 65 \mathrm{ClO} 4$ & 632.4571 & Linoleoyl-Linolenoyl-chloropropanediol \\
\hline $\mathrm{C} 35 \mathrm{H} 63 \mathrm{ClO} 4$ & 582.4415 & Myristoyl-Linoleoyl-chloropropanediol \\
\hline $\mathrm{C} 33 \mathrm{H} 63 \mathrm{ClO} 4$ & 558.4415 & Myristoyl-palmitoyl-chloropropanediol \\
\hline $\mathrm{C} 33 \mathrm{H} 63 \mathrm{ClO} 4$ & 558.4415 & Lauroyl-stearoyl-chloropropanediol \\
\hline $\mathrm{C} 35 \mathrm{H} 65 \mathrm{ClO} 4$ & 584.4571 & Myristoyl-oleoyl-chloropropanediol \\
\hline $\mathrm{C} 39 \mathrm{H} 71 \mathrm{ClO} 4$ & 638.5041 & Stearoyl-linoleoyl-chloropropanediol \\
\hline $\mathrm{C} 39 \mathrm{H} 73 \mathrm{ClO} 4$ & 640.5197 & Oleoyl-stearoyl-chloropropanediol \\
\hline $\mathrm{C} 39 \mathrm{H} 71 \mathrm{ClO} 4$ & 638.5041 & Linoleoyl-stearoyl-chloropropanediol \\
\hline $\mathrm{C} 37 \mathrm{H} 71 \mathrm{ClO} 4$ & 614.5041 & Palmitoyl-stearoyl-chloropropanediol \\
\hline $\mathrm{C} 37 \mathrm{H} 67 \mathrm{ClO} 4$ & 610.4728 & Palmitoyl-linoleoyl-chloropropanediol \\
\hline $\mathrm{C} 37 \mathrm{H} 65 \mathrm{ClO} 4$ & 608.4571 & Palmitoyl-linolenoyl-chloropropanediol \\
\hline $\mathrm{C} 35 \mathrm{H} 67 \mathrm{ClO} 4$ & 586.4728 & Myristoyl-stearoyl-chloropropanediol \\
\hline $\mathrm{C} 39 \mathrm{H} 71 \mathrm{ClO} 4$ & 638.5041 & Di-oleoyl-chloropropanediol \\
\hline C37H69ClO4 & 612.4884 & Oleoyl-palmitoyl-chloropropanediol \\
\hline $\mathrm{C} 39 \mathrm{H} 75 \mathrm{ClO} 4$ & 642.5354 & Di-stearoyll-chloropropanediol \\
\hline $\mathrm{C} 39 \mathrm{H} 67 \mathrm{ClO} 4$ & 634.4728 & Oleoyl-linolenoyl-chloropropanediol \\
\hline $\mathrm{C} 39 \mathrm{H} 69 \mathrm{ClO} 4$ & 636.4884 & Oleoyl-linoleoyl-chloropropanediol \\
\hline $\mathrm{C} 37 \mathrm{H} 69 \mathrm{ClO} 4$ & 612.4884 & Oleyl-palmitoyl-chloropropanediol \\
\hline \multicolumn{2}{|c|}{ Glycidyl esters (GEs) } & \\
\hline $\mathrm{C} 15 \mathrm{H} 28 \mathrm{O} 3$ & 256.2038 & Glycidyl laurate \\
\hline $\mathrm{C} 17 \mathrm{H} 32 \mathrm{O} 3$ & 284.2351 & Glycidyl myristate \\
\hline $\mathrm{C} 21 \mathrm{H} 40 \mathrm{O} 3$ & 340.2977 & Glycidyl stearate \\
\hline C19H36O3 & 312.2664 & Glycidyl palmitate \\
\hline $\mathrm{C} 21 \mathrm{H} 38 \mathrm{O} 3$ & 338.2821 & Glycidyl oleate \\
\hline $\mathrm{C} 21 \mathrm{H} 36 \mathrm{O} 3$ & 336.2664 & Glycidyl linoleate \\
\hline $\mathrm{C} 21 \mathrm{H} 34 \mathrm{O} 3$ & 334.2508 & Glycidyl linoleate \\
\hline
\end{tabular}

FbF algorithm found all six GEs and MCPDEs in the calibration standards, thereby validating the data analysis process (see Figure 1). Our method was capable of detecting GEs and di-MCPDEs down to $2 \mathrm{ng} / \mathrm{mL}$ and mono-MCPDEs down to $5 \mathrm{ng} / \mathrm{mL}$ concentrations. 


\subsection{Analysis of Glycerin Samples}

The refined and crude glycerin samples we obtained were diluted and subjected to the same screening procedure as the calibration standards. The screen against the database using $\mathrm{FbF}$ algorithm produced many false-positive hits for GEs that were eliminated by comparing the retention time and mass accuracy with standards. There were no hits for MCPDEs.

The data generated in the study were validated according to the HRMS guidance [32]. The mass accuracy was $<5 \mathrm{ppm}$ for all six compounds in the calibration standards. Each sample was analyzed in triplicate. The retention time shift was $<0.2$ min between the replicate injections. The detected levels were reproducible. The compound stability was monitored throughout the study by injecting the stock solutions of standards in methanol during the course of the study, and no instability was detected.

\section{Materials and Methods}

\subsection{Materials}

3.1.1. Instrumentation

Samples were analyzed using an Agilent 1290 Infinity UHPLC coupled with 6550 Q-TOF mass spectrometer (Agilent Technologies, Palo Alto, CA, USA) in positive-ion mode.

\subsubsection{Chemicals}

Glycidyl linolenate (CAS 51554-07-5), glycidyl linoleate (CAS 243085-63-3), 1-lauroyl-3chloropropanediol (CAS 20542-96-5), 1-palmitoyl-3-chloropropanediol (CAS 30557-04-1), 2oleoyl-3-chloropropanediol (CAS 915297-48-2), 1-palmitoyl-2-stearoyl-3-chloropropanediol (CAS 1185060-41-6), 1-oleoyl-2-stearoyl-3-chloropropanediol (CAS 1336935-05-7), and 1,2distearoyl-3-chloropropanediol (CAS 72468-92-9) were purchased from Toronto Research Chemicals (Toronto, ON, Canada).

\subsubsection{Glycerin Samples}

Sixteen food-grade glycerin samples and four crude-grade glycerin samples were obtained from various sources. A food-grade glycerin sample obtained from Procter \& Gamble (Cincinnati, OH, USA) was used for constructing matrix calibration curves for the mixed standard.

\subsection{Preparation of Stock Solutions and Working Standards}

Primary stock solutions ( $1 \mathrm{mg} / \mathrm{mL}$ each) were prepared separately by dissolving the ester standard in methanol. There are two classes of MCPDEs, namely mono- and diesters. Two GEs (glycidyl linoleate and glycidyl linolenate), two MCPD monoesters (1palmitoyl-3-chloropropanediol and 2-oleoyl-3-chloropropanediol), and two MCPD diesters (1-oleoyl-2-stearoyl-3-chloropropanediol and 1-palmitoyl-2-stearoyl-3-chloropropanediol) were selected to represent the two classes of MCPDEs and GEs. Working standard solutions were prepared at $50,100,500$, and $1,000 \mu \mathrm{g} / \mathrm{mL}$ by diluting appropriate volumes of the primary stock solution with $\mathrm{MeOH}$. All solutions were stored in glass vials at $4{ }^{\circ} \mathrm{C}$ or below.

\subsection{Preparation of a Calibration Curve of the Mixed Standard in Glycerin and Methanol}

Appropriate amounts of working standards of MCPDEs and GEs were spiked (added) into methanol and glycerin matrix to produce the following concentrations: 2, 5, 10, 25, 50, 125,250 , and $400 \mathrm{ng} /$ glycerin. Mixed standard in glycerin was prepared using $1 \mathrm{~g}$ food grade glycerin (Procter and Gamble) in $2 \mathrm{~mL}$ methanol, spiked with appropriate volumes of working standards.

Calibration curves were constructed in both methanol and glycerin matrix.

\subsection{Glycerin Sample Preparation for Screening for MCPDEs and GEs}

Sixteen food-grade glycerin samples and four crude-grade glycerin samples (approximately $1 \mathrm{~g}$ each) were prepared separately in $4 \mathrm{~mL}$ glass amber vials. Each $1 \mathrm{~g}$ glycerin was 
weighed directly into the vial, and $500 \mu \mathrm{L}$ of methanol was pipetted into each vial. Vials were capped and vortexed, and methanol was added dropwise to bring the total volume of each sample up to the $2 \mathrm{~mL}$ mark. Methanol was used as the solvent blank. Triplicate injections were performed for each sample.

\subsection{UHPLC Analysis}

We analyzed the diluted spiked glycerin without solid-phase extraction step using the QTOF6500 HRMS mass spectrometer coupled to the UHPLC system. A liquid chromatography system 1290 (Agilent Technologies, Santa Clara, CA, USA) with a BEHC18 column $\left(2.0 \mathrm{~mm} \times 100 \mathrm{~mm}\right.$ ) with $1.8 \mu \mathrm{m}$ particles (Waters, Milford, MA, USA) at $30{ }^{\circ} \mathrm{C}$ was used for HPLC separation. Mobile phase A consisted of 92:8 methanol/water with $0.05 \%$ formic acid; mobile phase B consisted of 98:2 isopropanol/water with $0.05 \%$ formic acid. The flow rate was $300 \mu \mathrm{L} / \mathrm{min}$, and the gradient used was as follows: from 0-3 min, mobile phase B 0-30\%; from 3-10 min, mobile phase B 30-70\%, followed by holding at 70\% B for 5 min and returning to $0 \% \mathrm{~B}$ in $2 \mathrm{~min}$. The first $1 \mathrm{~min}$ of the LC flow was diverted to the waste to prevent the glycerin matrix from entering the mass spectrometer.

\subsection{HRMS Analysis}

The Agilent 6550 QTOF instrument (Agilent Technologies, Santa Clara, CA, USA) is equipped with an Agilent Jet Stream Technology Dual Spray ESI source and an iFunnel. The instrument was calibrated in the extended dynamic range $(2 \mathrm{GHz}$, High Res Mode) and lower mass range $(m / z<1700)$ in the positive ion mode. Data were collected in centroid format. Reference masses at $\mathrm{m} / \mathrm{z} 121.0509$ and $\mathrm{m} / \mathrm{z} 922.0089$ were continually introduced via a second sprayer for accurate mass calibration. The reference ions used were purine $\left(\mathrm{C}_{5} \mathrm{H}_{4} \mathrm{~N}_{4}\right)$ at $m / z 121.0509$ and HP-921 (hexakis- $(1 \mathrm{H}, 1 \mathrm{H}, 3 \mathrm{H}$-tetrafluoropentoxy)phosphazene $\left.\left(\mathrm{C}_{18} \mathrm{H}_{18} \mathrm{O}_{6} \mathrm{~N}_{3} \mathrm{P}_{3} \mathrm{~F}_{24}\right)\right)$ at $\mathrm{m} / \mathrm{z} 922.0089$ for positive mode. The source conditions were as follows: sheath gas flow, $11 \mathrm{~L} \mathrm{~min}^{-1}$; sheath gas temperature, $350{ }^{\circ} \mathrm{C}$; nebulizer pressure, $40 \mathrm{psi}$; drying gas temperature, $150{ }^{\circ} \mathrm{C}$; drying gas flow, $15 \mathrm{~L} \mathrm{~min}^{-1}$; nozzle voltage, $380 \mathrm{~V}$; fragmentor voltage, $360 \mathrm{~V}$; capillary voltage, $3500 \mathrm{~V}$. Nitrogen was used as source gas and as collision gas. Full scan MS were acquired over the mass range $m / z$ 100-1000 at a scan speed of 2 scans/s. Agilent Mass Hunter workstation software version B.05.00 was used for data acquisition, and B.06.00 qualitative analysis was used for processing. Mass calibration was performed prior to analysis.

\section{Conclusions}

We accomplished our goal in this study by successfully developing a UHPLC/QTOF-based screening method to detect a variety of GEs and MCPDEs in glycerin samples (both crude and refined grades). It is a dilute-and-shoot method with minimal sample preparation that can be adapted to other matrices. The screening method by FbF against our in-house library produced many false positives for GEs, which were eliminated by comparing the retention times with standards. There were no hits for MCPDEs in the limited glycerin samples we analyzed.

Author Contributions: L.G., K.H., and H.J. conceptualized the study and planned the laboratory work; L.G. executed LCMS method development; L.G. and H.J. worked with the Mass Hunter software and $\mathrm{FbF}$ algorithm for data processing; L.G., H.J., and K.H. prepared the original draft. All the authors (L.G., K.H., H.E., R.R., O.C., and H.J.) reviewed and edited the manuscript. All authors have read and agreed to the published version of the manuscript.

Funding: This research received no external funding.

Institutional Review Board Statement: Not applicable.

Informed Consent Statement: Not applicable.

Data Availability Statement: Not applicable. 
Acknowledgments: We thank Philip J. Kijak for administrative support and Matthew Bell for assistance in the graphical design of figures.

Conflicts of Interest: The authors declare no conflict of interest.

Sample Availability: Samples of the compounds are available from the authors.

\section{References}

1. FDA. Food and Drug Administration Investigates Animal Illnesses Linked to Jerky Pet Treats. 2018. Available online: https: //www.fda.gov/AnimalVeterinary/NewsEvents/ucm360951.htm (accessed on 12 March 2020).

2. FDA. Jerky Pet Treat Investigation Testing Rationale and Results for October 1, 2013-December 31, 2015. 2016. Available online: https:/ / www.fda.gov/media/97687/download (accessed on 15 May 2020).

3. Carmichael, N.; Lee, J.; Giger, U. Fanconi syndrome in dog in the UK. Vet. Rec. 2014, 174, 357-358. [CrossRef]

4. Abraham, L.A.; Tyrrell, D.; Charles, J.A. Transient renal tubulopathy in a racing Greyhound. Aust. Vet. J. 2006, 84, 398-401. [CrossRef]

5. Thompson, M.F.; Fleeman, L.M.; Kessell, A.E.; Steenhard, L.A.; Foster, S.F. Acquired proximal renal tubulopathy in dogs exposed to a common dried chicken treat: Retrospective study of 108 cases (2007-2009). Aust. Vet. J. 2013, 91, 368-373. [CrossRef]

6. Hooper, A.N.; Roberts, B.K. Fanconi syndrome in four non-basenji dogs exposed to chicken jerky treats. J. Am. Anim. Hosp. Assoc. 2011, 47, e178-e187. [CrossRef]

7. Herath, K.; Girard, L.; Reimschuessel, R.; Jayasuriya, H. Application of time-of-flight mass spectrometry for screening of crude glycerins for toxic phorbol ester contaminants. J. Chromatogr. B Analyt. Technol. Biomed. Life Sci. 2017, 1046, 226-234. [CrossRef]

8. Hrncirik, K.; van Duijn, G. An initial study on the formation of 3-MCPD esters during oil refining. Eur. J. Lipid Sci. Technol. 2011, 113, 374-379. [CrossRef]

9. Arisseto, A.P.; Marcolino, P.F.; Vicente, E. 3-Monochloropropane-1,2-diol fatty acid esters in commercial deep-fat fried foods. Food Addit. Contam. Part A 2015, 32, 1431-1435. [CrossRef] [PubMed]

10. Mogol, B.A.; Pye, C.; Anderson, W.; Crews, C.; Gokmen, V. Formation of monochloropropane-1,2-diol and its esters in biscuits during baking. J. Agric. Food Chem. 2014, 62, 7297-7301. [CrossRef]

11. Hamlet, C.G.; Sadd, P.A.; Crews, C.; Velisek, J.; Baxter, D.E. Occurrence of 3-chloro-propane-1,2-diol (3-MCPD) and related compounds in foods: A review. Food Addit. Contam. 2002, 19, 619-631. [CrossRef] [PubMed]

12. Baer, I.B.; Calle, B.D.L.; Taylor, P. 3-MCPD in food other than soy sauce or hydrolysed vegetable protein (HVP). Anal. Bioanal. Chem. 2010, 396, 443-456. [CrossRef] [PubMed]

13. Dubois, M.; Tarres, A.; Goldmann, T.; Empl, A.M.; Donaubauer, A.; Seefelder, W. Comparison of indirect and direct quantification of esters of monochloropropanediol in vegetable oil. J. Chromatogr. A 2012, 1236, 189-201. [CrossRef] [PubMed]

14. Hoogenboom, L. EFSA Panel on Contaminants in the Food Chain. Risks for human health related to the presence of 3- and 2-monochloropropanediol (MCPD), and their fatty acid esters, and glycidyl fatty acid esters in food. EFSA J. 2016, 14, e04426. [CrossRef]

15. Knutsen, H.K.; Alexander, J.; Barregård, L.; Bignami, M.; Brüschweiler, B.; Ceccatelli, S.; Cottrill, B.; Dinovi, M.; Edler, L.; Grasl-Kraupp, B.; et al. Update of the risk assessment on 3-monochloropropane diol and its fatty acid esters. EFSA J. 2018, 16, e05083. [CrossRef] [PubMed]

16. Barocelli, E.; Corradi, A.; Mutti, A.; Petronini, P.G. Comparison between 3-MCPD and its palmitic esters in a 90-day toxicological study. EFSA Support. Publ. 2011, 8, 187E. [CrossRef]

17. Liu, M.; Gao, B.-Y.; Qin, F.; Wu, P.-P.; Shi, H.-M.; Luo, W.; Ma, A.-N.; Jiang, Y.-R.; Xu, X.-B.; Yu, L.-L. Acute oral toxicity of 3-MCPD mono- and di-palmitic esters in Swiss mice and their cytotoxicity in NRK-52E rat kidney cells. Food Chem. Toxicol. 2012, 50, 3785-3791. [CrossRef]

18. Abraham, K.; Appel, K.E.; Berger-Preiss, E.; Apel, E.; Gerling, S.; Mielke, H.; Creutzenberg, O.; Lampen, A. Relative oral bioavailability of 3-MCPD from 3-MCPD fatty acid esters in rats. Arch. Toxicol. 2013, 87, 649-659. [CrossRef]

19. Onami, S.; Cho, Y.M.; Toyoda, T.; Akagi, J.; Fujiwara, S.; Ochiai, R.; Tsujino, K.; Nishikawa, A.; Ogawa, K. Orally administered glycidol and its fatty acid esters as well as 3-MCPD fatty acid esters are metabolized to 3-MCPD in the F344 rat. Regul. Toxicol. Pharmacol. 2015, 73, 726-731. [CrossRef]

20. Bakhiya, N.; Abraham, K.; Gurtler, R.; Appel, K.E.; Lampen, A. Toxicological assessment of 3-chloropropane-1,2-diol and glycidol fatty acid esters in food. Mol. Nutr. Food Res. 2011, 55, 509-521. [CrossRef]

21. Mahmoud, Y.I.; Abo-Zied, F.S.; Salem, S.T. Effects of subacute 3-monochloropropane-1,2-diol treatment on the kidney of male albino rats. Biotech. Histochem. 2019, 94, 199-203. [CrossRef]

22. Irwin, R.D.; Eustis, S.L.; Stefanski, S.; Haseman, J.K. Carcinogenicity of glycidol in F344 rats and B6C3F1 mice. J. Appl. Toxicol. 1996, 16, 201-209. [CrossRef]

23. Zhao, Y.; Zhang, Y.; Zhang, Z.; Liu, J.; Wang, Y.L.; Gao, B.; Niu, Y.; Sun, X.; Yu, L. Formation of 3-MCPD Fatty Acid Esters from Monostearoyl Glycerol and the Thermal Stability of 3-MCPD Monoesters. J. Agric. Food Chem. 2016, 64, 8918-8926. [CrossRef]

24. Mbamalu, V.C. Glycerin and the Market. Master's Thesis, The University of Tennessee at Chattanooga, Chattanooga, TN, USA, May 2013. 
25. Pudel, F.; Benecke, P.; Fehling, P.; Freudenstein, A.; Matthäus, B.; Schwaf, A. On the necessity of edible oil refining and possible sources of 3-MCPD and glycidyl esters. Eur. J. Lipid Sci. Technol. 2011, 113, 368-379. [CrossRef]

26. Destaillats, F.; Craft, B.D.; Sandoz, L.; Nagy, K. Formation mechanisms of monochloropropanediol (MCPD) fatty acid diesters in refined palm (Elaeis guineensis) oil and related fractions. Food Addit. Contam. Part A 2012, 29, 29-37. [CrossRef]

27. Destaillats, F.; Craft, B.D.; Dubois, M.l.; Nagy, K. Glycidyl esters in refined palm (Elaeis guineensis) oil and related fractions. Part I: Formation mechanism. Food Chem. 2012, 131, 1391-1398. [CrossRef]

28. MacMahon, S.; Mazzola, E.; Begley, T.H.; Diachenko, G.W. Analysis of processing contaminants in edible oils. Part 1. Liquid chromatography-tandem mass spectrometry method for the direct detection of 3-monochloropropanediol monoesters and glycidyl esters. J. Agric. Food Chem. 2013, 61, 4737-4747. [CrossRef] [PubMed]

29. MacMahon, S.; Begley, T.H.; Diachenko, G.W. Analysis of processing contaminants in edible oils. Part 2. Liquid chromatographytandem mass spectrometry method for the direct detection of 3-monochloropropanediol and 2-monochloropropanediol diesters. J. Agric. Food Chem. 2013, 61, 4748-4757. [CrossRef] [PubMed]

30. MacMahon, S.; Ridge, C.D.; Begley, T.H. Liquid chromatography-tandem mass spectrometry (LC-MS/MS) method for the direct detection of 2-monochloropropanediol (2-MCPD) esters in edible oils. J. Agric. Food Chem. 2014, 62, 11647-11656. [CrossRef] [PubMed]

31. Hori, K.; Matsubara, A.; Uchikata, T.; Tsumura, K.; Fukusaki, E.; Bamba, T. High-throughput and sensitive analysis of 3monochloropropane-1,2-diol fatty acid esters in edible oils by supercritical fluid chromatography/tandem mass spectrometry. $J$. Chromatogr. A 2012, 1250, 99-104. [CrossRef] [PubMed]

32. FDA. Acceptance Criteria for Confirmation of Identity of Chemical Residues using Exact Mass Data within the Office of Foods and Veterinary Medicine. 2015. Available online: https://www.fda.gov/media/96499/download (accessed on 20 August 2020). 